\title{
Risk management in Bavarian Alpine torrents: a framework for flood risk quantification accounting for subscenarios
}

\author{
Olga Špačková ${ }^{1}$, Andreas Rimböck ${ }^{2}$, Daniel Straub ${ }^{1}$ \\ ${ }^{1}$ Engineering Risk Analysis Group, Technische Universitait München, Germany \\ ${ }^{2}$ Bavarian Environment Agency, Germany
}

The flood risk is typically assessed by evaluating a few basic flood scenarios such as HQ30, HQ100 and HQ300. The damage assessment for these scenarios is associated with high uncertainty. This uncertainty is for example due to uncertainty in predicting the course of the event (e.g. potential bridge blockage, failures of protection measures, the amount of transported solid material) or due to limited information about the area and limited model accuracy. To account for these uncertainties, the concept of subscenarios can be used. In this paper, we summarize the principle of risk approximation using basic HQ scenarios and we extend this formulation to account for subscenarios. The procedure is demonstrated through a numerical example of flood risk estimation in a hypothetical mountain torrent.

Keywords: floods, risk quantification, mountain torrents, sub-scenarios, return period

\section{Introduction}

The Bavarian authorities consider updating the current strategy for planning and management of flood protection measures in Alpine torrents. A new guidance is therefore being developed as a joint work of specialists in water management, hydrology, engineering geology and risk analysis.

An important aspect of flood protection planning and management is the quantification of risk. At present, the flood risk is typically approximated by evaluating a few basic flood scenarios such as HQ30, HQ100 and HQ300 (Merz et al., 2009). This approach neglects the uncertainties in the modelling of the flood scenarios, which can lead to inaccuracies in the risk estimates. In mountain torrents, these uncertainties are especially high. E.g., under a change of an uncertain boundary condition, the torrent can change its nature from a flood with bedload transport to a dynamic debris flow. Or potential (and highly uncertain) log jams at narrow passages of the torrent can drastically alter the course of event and the resulting dam- 
age - example of such an event is the flood in Brig, Switzerland in 1993 (Bezzola et al., 1994). To cover such uncertainties, it may be necessary to consider further subscenarios beyond the classical HQ scenarios.

The concept of subscenarios was described in a Swiss methodology for landslide risk assessment (Heinimann et al., 1999). It was further used for development of flood risk maps, i.e. for a semi-quantitative risk assessment, in (Hübl et al., 2004). A Swiss guideline for surface water risk assessment (Rüttimann, 2010) recommends utilization of scenarios and subscenarios for modeling the uncertainty in the rainfall characteristics and in the antecedent soil moisture conditions. A rigorous formulation of the risk estimation is, however, missing in these studies.

In this paper, we summarize the principle of risk estimation using basic HQ scenarios and we extend this formulation to account for subscenarios. A numerical example of flood risk estimation in a hypothetical mountain torrent illustrates the effect of the subscenarios on the risk estimation.

\section{Scenario-based flood risk assessment}

Flood risk is defined as the expected annual damage (EAD) caused by floods (Merz et al., 2009). Flood events leading to damage are typically rare and the possibility of occurrence of more than one flood event leading to damage within one year can thus be neglected. The annual risk (i.e. the expected damage in one year) can then be calculated as

$R=\int_{0}^{\infty} D(q) f_{Q}(q) \mathrm{d} q$

where $q$ is the annual maximum discharge, $f_{Q}(q)$ is the probability density function (PDF) of the annual maximum discharge and $D(q)$ is the damage function expressing the expected value of the damage as a function of the discharge. The units of the risk are the same as units of the damage function, here we consider monetary damages expressed in Euro. Example PDFs of annual maximum discharge and the damage functions are shown in Fig. 1.

Exact calculation of Eq. (1) is impossible in most practical application, mainly because the determination of the damage function $D(q)$ may be computationally demanding and requires significant effort on data investigation. It is therefore common practice to approximate the integral in Eq. (1) based on the evaluation of a limited number of HQ scenarios. The $i$ th scenario is described by its return period $T_{i}$, the discharge $Q_{T_{i}}$ and the estimated damage $D_{T_{i}}=D\left(Q_{T_{i}}\right)$. The return period is the inverse of the annual exceedance probability $p_{T_{i}}=\operatorname{Pr}\left[Q>Q_{T_{i}}\right]=1 / T_{i}$. The most commonly applied scenario is the hundred-year flood event, denoted as HQ100, which corresponds to a discharge $Q_{100}$ with a return period $T=100$ years. Other typically used scenarios are depicted in Fig. 1. 


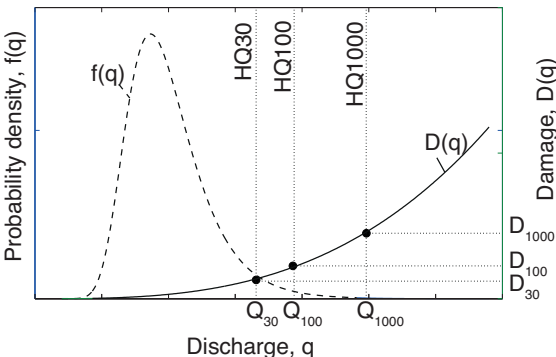

(a)

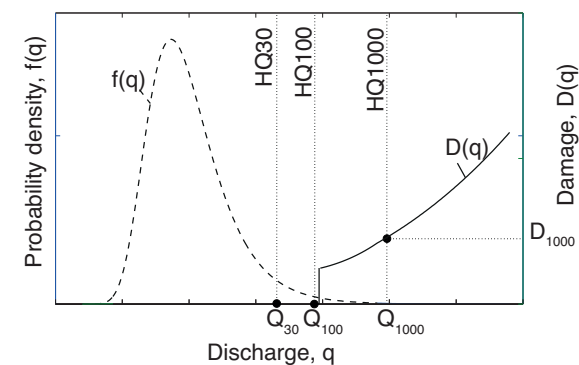

(b)

Fig. 1. Scenario-based risk approximation. PDF of annual maximum discharge, the damage function and the typically used HQ scenarios: (a) in a catchment without flood protection, (b) in a catchment that is fully protected against HQ100.

The scenarios are ordered from the lowest return period to the highest, $p_{T_{i}}>p_{T_{i+1}}$, and it holds $D_{T_{i+1}}>D_{T_{i}}$. The risk can be approximated using $N$ scenarios as:

$R \approx \sum_{i=1}^{i=N-1}\left(p_{T_{i}}-p_{T_{i+1}}\right) \frac{\left(D_{T_{i+1}}+D_{T_{i}}\right)}{2}+p_{T_{N}} D_{T_{N}}$

The quality of the approximation depends on the selection of scenarios. These should be chosen in such a way that they cover the entire damage function. Therefore, the first scenario (the scenario with the lowest return period) should correspond to the lowest discharge that causes damages.

\section{Accounting for subscenarios}

In reality, multiple uncertainties are present in the modelling of a flood event and the prediction of the associated damage. These uncertainties can be divided into two groups: (1) Aleatory uncertainties that represent the natural randomness of the analysed system, such as the amount of soil and organic materials deposited in the catchment at the time of the event, the performance of the protection measures or the possible presence of obstacles in the river bed. (2) Epistemic uncertainties that arise from the limited knowledge of the analyst about the system and from model errors. These are especially relevant in the early phase of the analysis or if only a less detailed study is carried out, i.e. when there is a little information about the system and the relevant processes.

Taking into account these uncertainties, Eq. (1) can be rewritten as

$R=\int_{0}^{\infty} D(q) f_{Q}(q) \mathrm{d} q=\int_{0}^{\infty}\left(\int_{0}^{\infty} f_{D}(d \mid q) \mathrm{d} d\right) f_{Q}(q) \mathrm{d} q$

where $f_{D}(d \mid q)$ is the PDF of the damage for given discharge $q$ and $f_{Q}(q)$ is the PDF of the annual maximum discharge. Fig. 2(a) illustrates the uncertainty of the damage for different values of discharge $q$. The PDFs of damage are illustrated as 
bi-modal. This bi- (or multi-) modality is a common phenomenon that represents a sudden increase of damage in case of a discrete event such as the failure of a protection measure or the blockage of a bridge. It can also be due to epistemic uncertainty, where, for example, without a detailed topographical survey and hydrological model, the analyst is not sure whether the right or left side of the stream would be flooded.

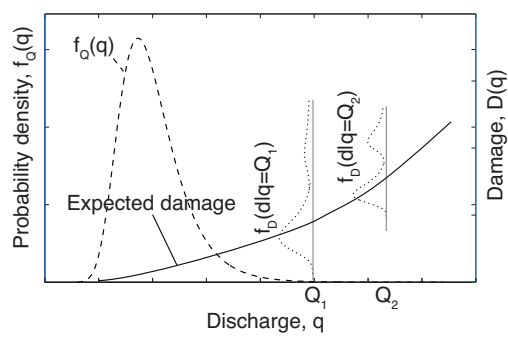

(a)

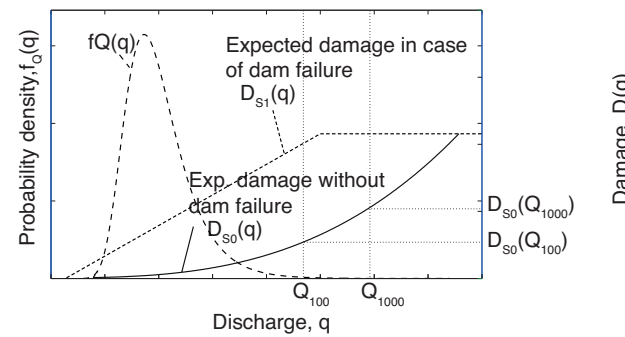

(b)

Fig. 2. (a) Uncertainty in the damage assessment (b) Representation of the uncertainty using subscenarios: the expected damage for basic scenario is shown with a solid line, the expected damage for the subscenario representing the possibility of dam failure is shown with a dashed line.

These discrete phenomena (failure of a protection measure, bridge blockage etc.) can be represented by so-called subscenarios as shown in Fig. 2(b). The subscenarios represent mutually exclusive events (or combinations of events) that can potentially occur at the given discharge $q$. For the $j$ th subscenario, the conditional expected damage $D_{S_{j}}(q)$ and the probability of occurrence $p_{S_{j}}(q)$ is estimated. The expected damage accounting for subscenarios can be calculated as:

$D(q)=\sum_{j=1}^{j=M} p_{S_{j}}(q) D_{S_{j}}(q)+\left(1-\sum_{j=1}^{j=M} p_{S_{j}}(q)\right) D_{S_{0}}(q)$

where $M$ is the total number of considered subscenarios and $D_{S_{0}}(q)$ is the expected damage for the basic scenario.

The risk can again be approximated with Eq. (2). The subscenarios are now included in the expected damage $D_{T_{i}}$ for $i$ th scenario through Eq. (4) and $D_{T_{i}}=$ $D\left(Q_{T_{i}}\right)$.

\section{Numerical example}

We are considering a mountain catchment that endangers a middle-size settlement. A simple scheme of the analysed area is shown in Fig. 3. The annual maximum discharge is described by a Weibull distribution with mean $10 \mathrm{~m}^{3} / \mathrm{s}$ and standard deviation $7 \mathrm{~m}^{3} / \mathrm{s}$; its PDF is shown in Fig. 6. Based on on-site investigation and hydrological and hydraulic analyses, the flooded area can be determined and the 
damages can be assessed as a function of the flooded area. The capacity of the stream is $15 \mathrm{~m}^{3} / \mathrm{s}$ (approximately corresponding to a 5-year flood); for this discharge, no damages are expected in the normal case (basic scenario). The valley surrounding the river has a convex shape, an exponential damage function is thus assumed (Merz et al., 2009). One part of the settlement is protected against a discharge of $Q_{D y k e}=32 \mathrm{~m}^{3} / \mathrm{s}$ (approximately corresponding to a 100-year flood) by a protection dike. For higher discharges, no protection is available (which causes the sudden increase in the damage function at $q=Q_{D y k e}$ by the additional damage $D_{\text {Dyke }}=3.10^{6}$ Euro). The damage function for the basic scenario, $D_{S_{0}}(q)$, is plotted in Fig. 4(a).

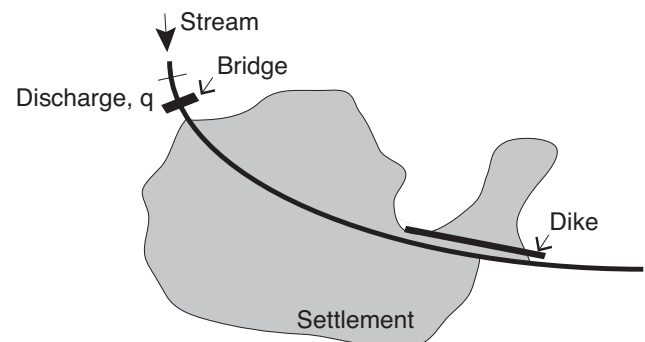

Fig. 3. Scheme of the analysed area.

The analyses identified two weak points in the catchment that can potentially lead to increased damages: (1) a bridge located at the entrance of the stream to the settlement, which can be blocked by the timber transported by the water; (2) a potential failure of the protection dike.

The probability of a bridge blockage, $p_{B B}(q)$, can be determined based on the ratio of the available and required free cross-section under the bridge following (Baudepartment St. Gallen, 2010). More detailed methods for bridge blockage probability assessment can be found for example in (Schmocker and Hager, 2011). The probability of the dike failure, $p_{D F}(q)$, can be assessed based on reliability analysis of the structure (Steenbergen et al., 2004; Jonkman et al., 2008). However, an exact assessment of these probabilities is impossible, all available methods are associated with high uncertainties.

Three subscenarios are identified: $s_{1}$ bridge blockage, $s_{2}$ dike failure and $s_{3}$ combination of both events. The probabilities of these scenarios can be calculated using the Event Tree Analysis (ETA) as shown in Fig. 5. The dependence of these probabilities on the discharge is depicted in Fig. 4(b).

The consequence of the bridge blockage (subscenario $s_{1}$ ) is estimated as an increase of the flooded area by $40 \%$. The damages of the subscenario $s_{1}$ are thus expressed as $D_{S_{1}}(q)=1.4 D_{S_{0}}(q)$. Subscenario $S_{2}$ (dike failure) leads to additional damage of $D_{D y k e}$ for discharges smaller than $Q_{D y k e}$, i.e. $D_{S_{2}}(q)=D_{S_{0}}(q)+D_{D y k e}$ for $q<Q_{D y k e}$ and $D_{S_{2}}(q)=D_{S_{0}}(q)$ otherwise. Finally, for Subscenario $s_{3}$, the 
damages are summed up and $D_{S_{3}}(q)=1.4 D_{S_{0}}(q)+D_{\text {Dyke }}$ for $q<Q_{\text {Dyke }}$ and $D_{S_{3}}(q)=1.4 D_{S_{0}}(q)$ otherwise. The damage functions are plotted in Fig. 4(a).

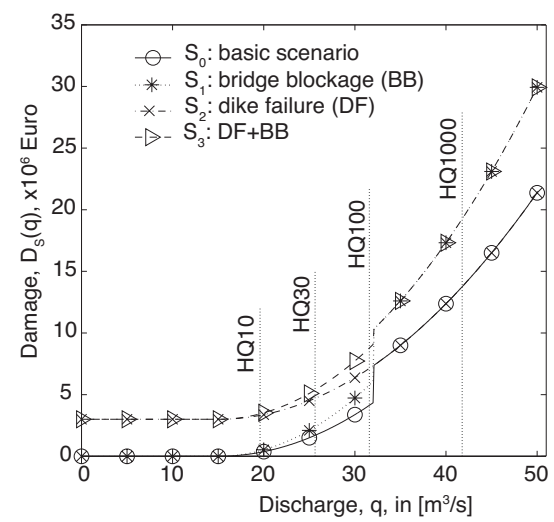

(a)

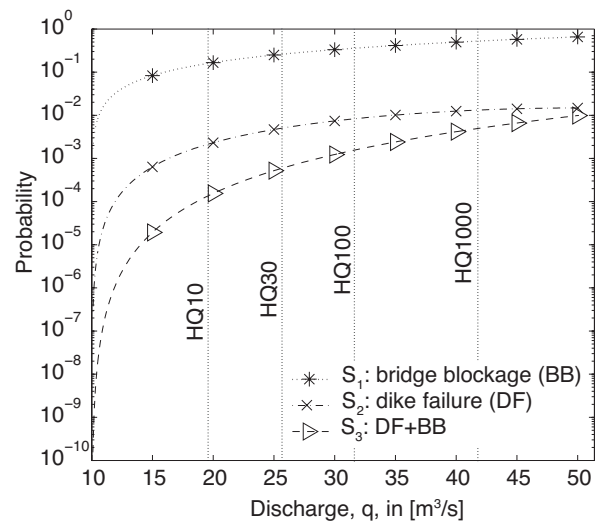

(b)

Fig. 4. (a) Damage functions $D(q \mid s)$ for basic scenario and subscenarios. (b) Probabilities of subscenarios, $p_{S_{j}}(q)$, as functions of discharge.

Note that the damage functions $D_{S_{2}}(q)$ and $D_{S_{3}}(q)$ associated with dike failure (DF) express the expected damage in case that the DF occurs and it is thus nonzero even for small discharges (see Fig. 4a). However, because the probability of DF for small discharges is equal or close to zero (see Fig. 4b), the unconditional expected damage $D(q)$ for small discharges is very small (see Fig. 6).

\begin{tabular}{|c|c|c|c|c|}
\hline & & & Scenario & Probability \\
\hline & & dike failure (DF) & $\mathrm{S}_{3}$ & $p_{s 3}(q)=p_{B B}(q)^{*} p_{D F \mid B B}(q)$ \\
\hline & bridge blockage (BB) & $\mathrm{p}_{\mathrm{DF} / \mathrm{BB}}(\mathrm{q})$ & & \\
\hline discharge, $\mathrm{q}$ & $p_{B B}(q)$ & no DF & $s_{1}$ & $p_{1}(q)=p_{p o}(q)^{*} p$ \\
\hline & & $p_{\neg D F \mid B B}(q)$ & $\mathrm{s}_{1}$ & ${ }_{\mathrm{S} 1}(4)-\mathrm{P}_{\mathrm{BB}}(\mathrm{Cl}) \mathrm{T}$ \\
\hline & & dike failure (DF) & $\mathrm{S}_{2}$ & $p_{\mathrm{s} 2}(q)=p_{-B B}(q)^{*} p_{D F I \neg B B}(q)$ \\
\hline & no BB & $p_{D F / \neg B}(q)$ & & \\
\hline & $p_{\neg B B}(q)$ & $\frac{\text { no } D F}{p_{\neg D F / \neg B B}(q)}$ & $\mathrm{s}_{0}$ & $p_{S 0}(q)=p_{\neg B B}(q)^{*} p_{\neg D F / \neg B B}(q)$ \\
\hline
\end{tabular}

Fig. 5. ETA for determining the probability of subscenarios.

\section{Results}

Fig. 6 illustrates the risk estimation for the numerical example. It displays the PDF of annual maximum discharge and the damage functions (i) excluding and (ii) including the subscenarios. The damage function for case (i) is identical to the dam- 
age function of basic scenario from Fig. 4(a). The damage function for case (ii) is higher, because the potential occurrences of bridge blockage and dike failure are taken into account using Eq. (4).

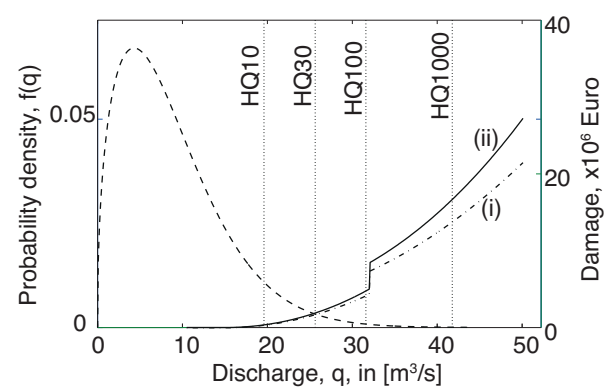

Fig. 6. Risk estimation (i) excluding and (ii) including subscenarios.

Tab. 1 summarizes the results of the analysis for analysed scenarios HQ10, HQ30, HQ100 and HQ100. It summarizes the corresponding discharges, $Q_{T_{i}}$, and the expected damage, $D_{T_{i}}$, for case (i) excluding the subscenarios and case (ii) including the subscenarios. Finally, Tab. 2 provides the resulting estimate of risk for both cases (i) and (ii).

Tab. 1. Inputs for risk approximation using Eq. (2).

\begin{tabular}{|c|c|c|c|c|}
\hline $\begin{array}{l}\text { Scenario } \\
\mathrm{HQT}_{\mathrm{i}}\end{array}$ & $\begin{array}{l}\text { Exceedance } \\
\text { probability } p_{T_{i}} \\
{\left[\text { year }^{-1}\right]}\end{array}$ & Discharge $Q_{T_{i}}$ & $\begin{array}{l}\text { Exp.damage } D_{T_{i}} \\
\text { excl. subsc. (i) } \\
{\left[10^{6} \text { Euro }\right]}\end{array}$ & $\begin{array}{l}\text { Exp.damage } D_{T_{i}} \\
\text { incl.subsc. (ii) } \\
{\left[10^{6} \text { Euro }\right]}\end{array}$ \\
\hline HQ10 & 0.1 & 19.6 & 0.32 & 0.34 \\
\hline HQ30 & 0.03 & 25.6 & 1.69 & 1.88 \\
\hline HQ100 & 0.01 & 31.6 & 4.13 & 4.76 \\
\hline HQ1000 & 0.001 & 41.8 & 13.77 & 16.69 \\
\hline
\end{tabular}

Tab. 2. Annual flood risk $\left[\times 10^{6}\right.$ Euro/year $]$.

\begin{tabular}{lll}
\hline & Excluding subscenarios & Including subscenarios \\
\hline (i) exact - Eq. (1) & 0.221 & 0.253 \\
(ii) approximation - Eq. (2) & 0.229 & 0.265 \\
\hline
\end{tabular}

The results in Tab. 2 show, that neglecting the subscenarios in the analysed example leads to underestimation of the risk of around $15 \%$. However, almost the same result would be obtained when including only the subscenario bridge blockage $\left(s_{1}\right)$. The other two subscenarios have minor impact on the results, because they are unlikely (the probability of subscenarios $s_{2}$ and $s_{3}$ is several orders of magnitude lower than that of scenario $s_{1}$, as can be seen from Fig. 5(b). The subscenarios with low probability and/or low impact (damage) can generally be neglected. 


\section{Conclusions}

A method for flood risk quantification was formulated that allows taking into account the uncertainties in the estimation of damages associated with flood events. An exact solution and an approximate approach based on evaluation of a few flood scenarios with different return periods, which is typically used in practice, are compared. The uncertainties are taken into account by evaluating a number of subscenarios representing for example a failure of a protection measure, log jam at a narrow passage of the river or a debris flow induced by the flood event. The subscenarios can also represent the uncertainty arising from limited information available at the time of the analysis, e.g. due to a simplified hydraulic model or an insufficient topographical survey. The concept is illustrated on a numerical example, which confronts the approximate method with the exact solution and it compares the classical risk estimate neglecting the uncertainties with the case when the subscenarios are included.

\section{References}

Baudepartment St. Gallen, 2010. Beurteilung der Verklausungsgefahr an einer Brücke.

Bezzola, G.R., Abegg, J., Jaeggi, M., 1994. Saltinabruecke Brig-Glis. Rekonstruktion des Hochwassers vom 24. September 1993 in Brig-Glis. Schweiz. Ing. Arch. - Schweiz. Bauztg. 112.

Heinimann, H.R., Bart, R., Borter, P., Egli, T., Gächter, M., 1999. Risikoanalyse bei gravitativen Naturgefahren-Methode.

Hübl, J., Ganahl, E., Gruber, H., Holub, M., Holzinger, G., Moser, M., Pichler, A., 2004. Risikomanagement Lattenbach: Risikoanalyse, IAN Report 95, Band 1.

Jonkman, S.N., Kok, M., Vrijling, J.K., 2008. Flood Risk Assessment in the Netherlands: A Case Study for Dike Ring South Holland. Risk Anal. 28, 1357-1374.

Merz, B., Elmer, F., Thieken, A.H., 2009. Significance of "high probability/low damage" versus "low probability/high damage" flood events. Nat Hazards Earth Syst Sci 9, 10331046.

Rüttimann, D., 2010. Wegleitung punktuelle Gefahrenabklärung Kanton Zürich: Oberflächenwasser.

Schmocker, L., Hager, W.H., 2011. Probability of Drift Blockage at Bridge Decks. J. Hydraul. Eng. 137, 470-479.

Steenbergen, H., Lassing, B., Vrouwenvelder, A., Waarts, P., 2004. Reliability analysis of flood defence systems. Heron 49, 51-73. 